\title{
AN ANATOMICAL RELATIONSHIP PREDISPOSING TO LUMBOSACRAL FUSION
}

\author{
FREDERICK P. THIEME \\ Department of Anthropology, University of Michigan, \\ Ann Arbor, Michigan \\ ONE FIGURE
}

Man has developed lumbar curvature as an essential part of fully erect posture. Yet it is not inherited as such, but developed anew in each individual as he learns to walk erect (Bardeen, '05). It seems that the essential spinal adjustment for typical human upright posture is one made during the life of the individual, and that it has not yet become a part of the human genetic heritage.

The functional requirements of erect posture, superimposed on a vertebral column inherited from primate ancestors, demand that skeletal and anatomical adjustments be made during' the life of each individual. As the form of the skeleton is closely related to its use or function, it is the purpose of this paper to investigate whether lumbosacral fusion is one such functional adaptation to the mechanical requirements of erect posture. In detail, it will examine the anatomical relationship which apparently is the weakness predisposing to anomalous lumbosacral fusion.

\section{BACKGROUND}

Erect posture has been a very early postural adaptation in the evolution of man. The pelvic bones of Australopithecus prometheus, together with the details of the limb bones and skull, indicate that this man-ape form walked erect (Dart, '49). In fact, from the evidence at hand, it is a fairly safe assumption that the very earliest fossil men, although transitional from anthropoid to modern man in skull capacity, were 
capable of fully erect posture. So, probably, only after the assumption of upright posture did the brain of man increase in size to the point that it certainly exceeded the anthropoid range.

In view of the evolutionary history of man and the importance of erect posture in that history, it is surprising to find that the lumbar curvature, without which man cannot stand erect, has not become an inherited anatomical feature. Possibly one fact that has made the phylogenetic adaptation unnecessary is that the breakdowns associated with lumbar instability come mainly in the later part of the reproductive period, and are rarely lethal. Yet many sections of the body have undergone considerable change with no greater apparent selective pressure. The evidence of erect posture can be found in all parts of the body and many of them are certainly genetically determined in pattern if not in final detail. There seem to be uneven rates of evolutionary adaptation within the anatomical regions of the body with the speed of evolutionary change being unrelated to their apparent functional importance.

Whatever may be the evolutionary position of lumbar curvature, it is a very important anatomical fact. This curve, introduced in a spine inherited from four-legged mamalian ancestors, has caused mechanical strains poorly met by the anatomical structure. No new muscles or ligaments have been acquired by man to meet the new functional requirements resulting from upright posture. However, important changes have occurred in the form of the skeleton, both in the spine and elsewhere. For instance, the reshaping and wedging of the lumbar vertebral segments during life is one such response to physiologic stresses. The development of the external tubercle of the tuber calcanci (Weidemreich, '40) is another such change brought about hy erect posture mechanics.

\section{LUMBOSACRAI FUSION}

Lumbosacral fusions are an anomalous development in the life span of some individuals and are quite common in adult 
populations (Willis, '23; Cushway and Maier, '29; Brailsford, '34; Hodges and Peck, '37; Williams, '37). The frequency is, in general, over $5 \%$ as seen in a variety of reported samples, and it increases with the mean age of the subjects. In this report, one sample with a mean age of 24.4 years shows a frequency of $10.9 \%$ and another of mean age 61.4 years is $18.3 \%$ ( see table 1 ).

These fusions are probably the result of normal bone growth in response to mechanical stress. The increase of any physiologic stress in the limits of tolerance acts as a growth stimulus on bone (Weinmann and Sicher, '47). In particular, fusing of the last lumbar segment to the sacrum or ilium is the culmination of a process of extensive marginal lipping, with the lines of extension probably following the ligaments. Whatever may be the detailed process of the formation of the bone, the result is to increase the security of the area. Murray ('36) has the following to say about the process of bone changes: ". . . There is no doubt that adult, fully formed bone, subjected to a changed pattern of mechanical stressing, can meet the new demands made upon it with a changed structure, and that the new morphological pattern so produced is, in respect of the new mode of stressing, more efficient than the old." (p. 134).

Inherited normal variation in skeletal structure gives some persons a superior pre-adaptation to the subsequent demands of erect posture. This is the condition of the majority of individuals in respect to the development of lumbosacral fusion. It is only a minority who inherit the mechanical relationship which predisposes them to eventual complete fusion. A greater number, by far, are involved with extensive marginal lipping which is the same response, to a lesser degree, to the stressing of erect posture. In fact, the general positive relationship of skeletal anomalies to excessive physiologic stress seems to explain the frequency and variety of most anomalies which concentrate in the lumbar region (Willis, '23). The development of many of these anomalies overlies the inherited variations and is apparently correlated inversely with the struc- 
tural or mechanical efficiency of the inherited structure. The fact that some persons develop lumbosacral fusions is evidence that they inherited structures inadequately stressed to the mechanical forces involved.

\section{MATERIALS AND METHODS}

In the course of a recent investigation the author (Thieme, '50) examined the mechanics of the lower lumbar region to discover whether some human disorders, including herniated intervertebral dises and spondylolisthesis, are associated with the evolutionary assumption of erect posture. As one part of this study, the mechanies of the lumbosacral region were examined to see if some deviant structural relationship could be considered the underlying cause of spondylolysis. This later aspect of the research, in contrast to the main investigation, proved negative. However, another outcome was the finding of a mechanical relationship highly correlated with lumbosacral fusion. This aspect of the original investigation has supplied the material for this report.

The author examined roentgenographic films of 55 adult male medical students ${ }^{1}$ (hereafter called "Students") without a history of low back pain, posed in relaxed erect posture in a standard position at a fixed distance from the ray source. In addition, 82 known male skeletons ${ }^{2}$ (with 66 of these of known race and age), prepared from dissecting room cadavers but of unknown medical history, were also examined and measured. In the films of the medical students, mathematical corrections were made to compensate for distortion and make both sample measurements comparable. However, as the skeletal material and the students are not compared in the analysis

\footnotetext{
${ }^{1}$ The films of the medical students were made available to the author through the courtesy of Dr. Robert P. Ball, Department of Roentgenology, Presbyterian Hospital, New York City. By making these films available, together with viewing facilities and much helpful advice, Dr. Ball made this compilation possible.

A portion of the collection of The Viking Fund and American Museum of Natural History sponsored Institute of Human Morphology.
} 
which follows, it is not essential that the x-ray and skeletal measurements be exactly comparable.

In the material that follows, the comparisons are made within the two quite different yet individually homogeneous samples. In each of the two sample populations the fusion cases are compared with the non-fusion cases to test the assumption that significant differences in important mechanical structures may be the causes of the fusion or non-fusion response.

The lumbosacral region, as a weight-bearing skeletal structure. was measured in relation to its mechanical functions. Weight forces passing down the spine are borne through the vertebral bodies and intervertebral discs and passed to the sacrum. They are then transmitted through the sacro-iliac arch to the acetabula, and thence down through the legs and feet. Between the superior sacral surface and the acetabulum, the pelvic brim, as marked by the iliopectineal or arcuate line, is the superior edge of the bony thickening which is important in supporting this weight.

By considering only the weight which is transmitted to the pelvis through the vertebrae, the mechanical problem is simplified. In norma lateralis the only pelvic structures relevant to weight support are the sacral superior surface, the thick bone between the sciatic notch, the superior brim of the true pelvis, and the acetabula. The pubic arch is vital in holding the pelvis in stability but is not directly involved in the transmission of weight forces.

In this problem only landmarks which are functionally related to mechanical weight bearing are included. Also, those marks were utilized which are clear on radiographic films and comparable to skeletal landmarks. The points and measurements, all from norma lateralis on the films, were taken as follows ${ }^{3}$ (see fig. 1) :

\footnotetext{
${ }^{3}$ Figure indicates the points and measures used in this investigation but does not show the considerable number which were taken in the original investigations and not pertinent here.
} 
Point A. The point at the intersection of the projected iliopectineal line and the anterior surface, or its projection, of the sacrum. ${ }^{*}$ (This point may lie superior to the sacrum and to the left of the sacral promontory in the diagram. In such cases the measurement [no. 1] is considered as negative.)

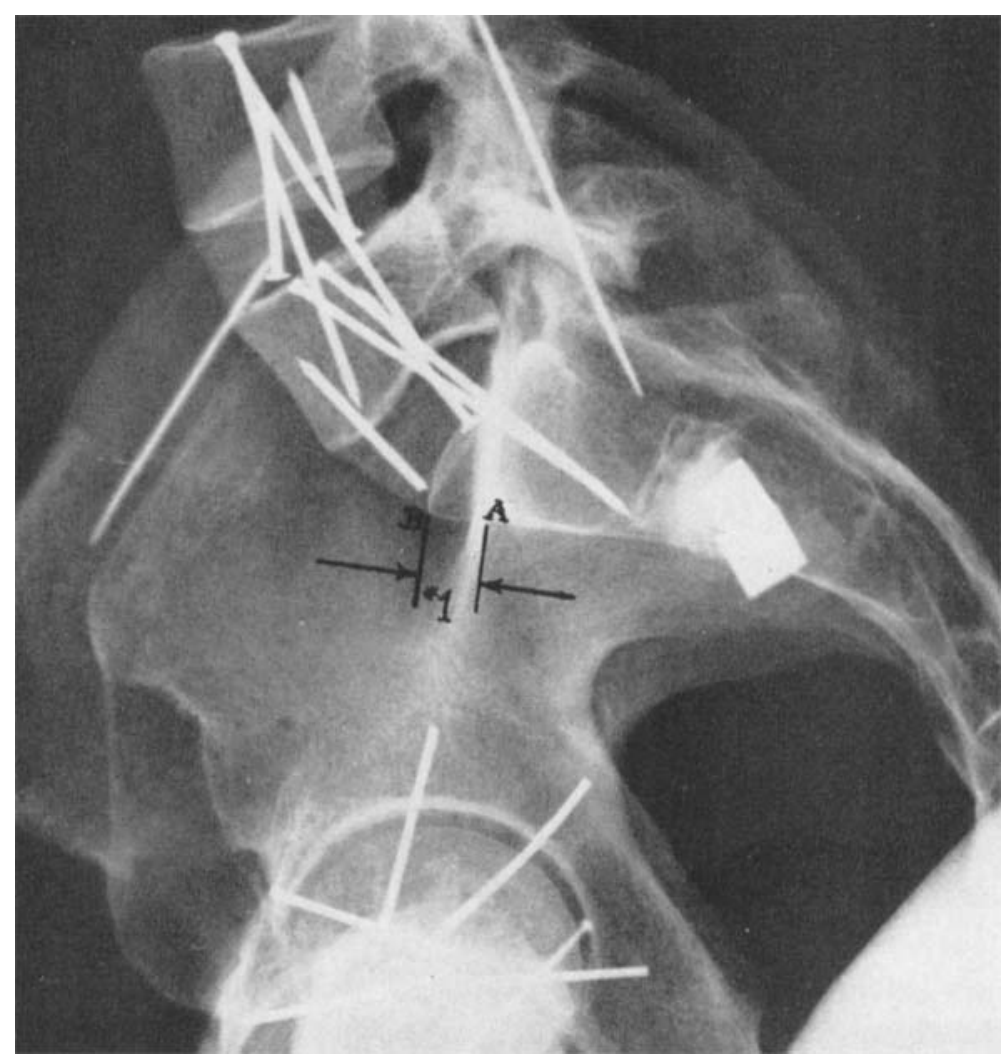

Figure 1

Point B. The sacral promontory.

Measurement no. 1. The distance from Point $A$ to Point $B$ (in millimeters).

- In the film this point is usually clear and corresponds to the top of the "saddle" which is lateral to the superior surface of the sacrum and is the continuation of the brim of the true pelvis. $X$-ray films make the use of this important weight bearing landmark possible on the living. Although it is not an easily defined landmark on skeletal material, it can be quite accurately found if the orientation of the pelvis in the $x$-ray film is kept in mind. 
RESULTS

The difference between the fusion and non-fusion cases in each sample is quite significant. Using the statistical test for difference, the values of the variance ratios, given as " $t$," are well beyond the $1 \%$ levels of probability and indicate the very strong likelihood that the differences are significant and not due to chance. The difference between the means of the "fused" compared to the "non-fused" in the "Students" is over $21 \mathrm{~mm}$. It is of considerable interest that the ranges of the two "Student" groups overlap in only one case $(5 \mathrm{~mm})$ so that, in this total sample, it would be possible to tell which were fusion cases merely by measuring the norma lateralis film, except in the one case.

It is strongly recommended because of the small size of the sample studied that other investigations be made to see if the results are as clear as they appear here. Yet at the same time it may be stated that the tests for significance take into account the small numbers of the sample. The results therefore are highly significant and certainly indicate that the differences found are not due to chance.

It would seem from these findings that if an individual has developed a sacrum which is recessed downward in relation to the true pelvis, resulting in a sacral promontory which does not project above the intersection of the arcuate line and the anterior sacrum, that he will probably develop a lumbosacral fusion. In fact, a projection of $5 \mathrm{~mm}$ or less in this measure (no. 1 in the diagram) is a strong indication that normal fusion will occur during the life of the individual.

The average age for the "Students" is 24.4 years, and for the skeletal series, where the age is known, is 61.4 years. This very marked age difference between the two samples probably accounts for the difference in the frequency of fusions, and also for the fact that the range of the measurements between the "fused" and the "non-fused" overlap more in the older sample. 
TABLE 1

Distance from the sacral promontory to the intersection of the arcuate line and the sacrum. (Distance no. 1 between points $A$ and $B$ )

\begin{tabular}{|c|c|c|c|c|c|c|}
\hline $\begin{array}{l}\text { SKRIES- } \\
\text { SAM PLE }\end{array}$ & $\begin{array}{l}\text { MEAN AND } \\
\text { BTANDARD } \\
\text { BRROR }{ }^{2}\end{array}$ & $\begin{array}{l}\text { BTANDARD } \\
\text { DEVIATION } \\
\text { AND ERROR }\end{array}$ & NUMB BKR & RANGE & $\begin{array}{c}\% \\
\text { FRE- } \\
\text { QuRNCY } \\
\text { OF } \\
\text { FugION }\end{array}$ & $\begin{array}{c}\text { VARIANCI } \\
\text { RATIO } \\
\text { OF } \\
\text { FUSED } \\
\text { TO } \\
\text { NON- } \\
\text { FUSED } 2\end{array}$ \\
\hline "Students" & & & & & $10.9 \%$ & 11.7 \\
\hline $\begin{array}{l}\text { Without } \\
\text { fusion }\end{array}$ & $19.96 \pm .34$ & $2.38 \pm .24$ & 49 & 5 to 39 & & \\
\hline $\begin{array}{l}\text { With } \\
\text { fusion }\end{array}$ & $-1.17 \pm 1.77$ & $4.34 \pm 1.26$ & 6 & -7 to +6 & & \\
\hline Difference & $21.13 \mathrm{~mm}$ & & & & & \\
\hline $\begin{array}{l}\text { Mluseum } \\
\text { skeletons }\end{array}$ & & & & & $18.3 \%$ & 5.5 \\
\hline $\begin{array}{l}\text { Without } \\
\text { fusion }\end{array}$ & $17.66 \pm .51$ & $4.15 \pm .36$ & 67 & 8 to 28 & & \\
\hline $\begin{array}{l}\text { With } \\
\text { fusion }\end{array}$ & $5.07 \pm 2.24$ & $8.69 \pm 1.59$ & 15 & -20 to +19 & & \\
\hline Difference & $12.59 \mathrm{~mm}$ & & & & & \\
\hline
\end{tabular}

1 The standard error added and subtracted from the mean and standard deviation gives an indication of the range within which two-thirds of the statistics of similarly sized random samples could be expected to fall when derived from the same parent population.

"The "variance ratio," a measure of the significance of difference, is computed by dividing the difference between the means being tested by the square root of the sum of the squares of the standard errors of the means. If the ratio is 2 , the odds are approximately one in 20 that the difference is due to ehance. Greater ratios make the possibility that there is a significant difference between the means more likely.

\section{DISCUSSION}

Point " A", the intersection of the line of the anterior sacrum and the arcuate line, in this analysis is a functional point related to the mechanical problem at hand and was not arbitrarily chosen because of ease of measurement or traditional antropometry. As the findings suggest, persons who have the 
point of intersection close to, or anterior to, the sacral promontory are predisposed to normal lumbosacral fusion.

A mechanical analysis indicates why this relationship exists. If the point of division of the forces that are transmitted down the spine and out to the right and left legs is anterior to the sacral promontory, the sacrum does not fully participate in the transmission of forces. The sacrum, then being out of the direct line of force, or partly so, does not perform its mechanical function normally. New bone, in effect a new superior sacral element build up in response to abnormal strain, bridges the last lumbar vertebra to the sacrum and/or ilium to give the security that the ligaments and connective tissue fail to give.

On mechanical grounds, it may be valid to say that the first sacral segment is the last segment in the spinal column which is directly involved with the division and transmission of compression forces from the spine to the legs. Also, the first sacral segment is the one with any part anterior to the intersection of the arcuate line and the anterior sacral surfaces. In other words, point " $\mathrm{B}$ " must be anterior to point " $\mathrm{A}$ " if it is truly the sacral promontory. If this relationship is not found in the individual, due to inherited skeletal variation, supporting fusion bone will be built up during his life span to give lumbosacral security. This process is clearly brought about by the mechanical requirements resulting from lumbar curvature and erect posture.

These findings indicate that the anomaly known as fusion of the lumbosacral joint can be added to the list of anatomical and skeletal changes during life resulting from the assumption of erect posture by man.

\section{ACKNOWLEDGEMENTS}

The author is indebted to Dr. S. L. Washburn for suggestions and guidance in this research, and to Dr. H. L. Shapiro for making the skeletal material available for study.

This research was done while the author was aided by a Pre-Doctoral Fellowship granted by The Viking Fund, an assistance which is gratefully acknowledged. 


\section{LITERATURE CITED}

BARDEen, C. R. 1905 Studies of the development of the human skeleton. Am. J. Anat., 4: 265.

Brailsford, J. F. 1934 and 1945 The Radiology of Bones and Joints. Baltimore, W. Wood and Co.

Cushway, B. C., AND R. J. Maikr 1929 Routine examinations of the spine for industrial employees. J. Am. Med. Assn., 92: 701.

DART, R. A. 1949 The first pelvic bones of Australopithecus prometheus: preliminary note. Am. J. Phys. Anthrop., n. s., 7: 255.

Hodgrs, F. J., AND W. S. PeCK 1937 Clinical and roentgenological study of low back pain with seiatic radiations. Am. J. Roentg., $37: 461$.

Murray, P. D. F. 1936 Bones: A Study of the Development and Structure of the Vertebrate Skeleton. Cambridge University Press.

Thieme, F. P. 1950 Lumbar Breakdown Caused by Erect Posture in Man. Anthropological Papers no. 4, Museum of Anthropology, University of Michigan.

WeIDENREICH, F. 1940 The external tubercle of the human tuber calcanei. Am. J. Phys. Anthrop., 26: 473.

Weinmann, J. P., And H. Sicher 1947 Bone and Bones. Fundamentals of Bone Biology. St. Louis, The C. V. Mosby Company.

Williays, P. C. 1937 Lesions of the lumbosacral spine. Part I and II, J. Bone and Joint Surg., $19: 343,690$.

WrLlis, T. A. 1923 The lumbo-sacral vertebral column in man: Its stability of form and function. Am. J. Anat., 32: 95.

\section{Mnd}

Early Stages in Human Evolution.-With a brain well within the human range it seems impossible to deny human status to the Swartkrans ape-man, and as he is clearly allied to the smaller-brained Australopithecus we seem to have at least two well-marked stages in the evolution of man.

In the next 5 or 10 years we ought to have many more stages, and to know fully the steps by which man evolved from a primate with a brain of $500 \mathrm{~cm}^{3}$ to one with over $1,000 \mathrm{~cm}^{3}$.- R. Broom and J. T. Robinson. One of the earliest types of man. South Afr. J. Sci., vol. 47 , no. 2,1950 , pp. 55-57. 